\title{
GIS modeling for canine dirofilariosis risk assessment in central Italy
}

\author{
Michele Mortarino ${ }^{1}$, Vincenzo Musella ${ }^{2}$, Valeria Costa ${ }^{1}$, Claudio Genchi ${ }^{1}$, Giuseppe \\ Cringoli ${ }^{3}$, Laura Rinaldi ${ }^{3}$ \\ ${ }^{1}$ DIPAV, Section of General Pathology and Parasitology, University of Milan, Milan, Italy; ${ }^{2}$ Department of \\ Clinical and Experimental Medicine, University of Catanzaro Magna Graecia, Catanzaro, Italy; \\ ${ }^{3}$ Department of Pathology and Animal Health, University of Naples "Federico II", Naples, Italy
}

\begin{abstract}
A survey was conducted in an area of central Italy in order to study the prevalence of Dirofilaria immitis and D. repens in dogs. Blood samples were collected from 283 dogs and examined using a modified Knott's technique. In addition, in order to detect $D$. immitis occult infection, 203 serum samples were also analysed for $D$. immitis antigen detection. The results were analyzed in order to evaluate the behavioural and attitudinal risk factors. A geographical information system (GIS) for the study area was constructed, utilizing the following data layers: administrative boundaries, elevation, temperature, rainfall and humidity. Microfilariae were detected in 32 of the 283 dogs surveyed, constituting a total Dirofilaria prevalence of $11.3 \%$. In particular, 20 dogs $(7.1 \%)$ were positive for D. immitis and 12 $\operatorname{dogs}(4.2 \%)$ for $D$. repens microfilariae. One case of $D$. immitis occult infection was also detected. Choroplethic municipal maps were drawn within the GIS in order to display the distribution of each Dirofilaria species in the study area. Statistical analysis showed a significant association between Dirofilaria infection and animal attitude (hunting/truffle dogs showed a higher prevalence compared to guard/pet dogs). A higher prevalence was also recorded in 2 to 5 -years old dogs. Furthermore a GIS-based modelling of climatic data, collected from 5 meteorological stations in the study area, was performed to estimate the yearly number of $D$. immitis generations in the mosquito vector. The results of the model as depicted by GIS analysis was highly concordant with the territorial distribution of positive dogs and showed that $D$. immitis spreading is markedly influenced by season. The potential transmission period in the study area was found to be confined to summer months with a peak in July and August, as expected for a temperate region where summer season is the most favourable period for the parasite.
\end{abstract}

Keywords: Dirofilaria immitis, Dirofilaria repens, dog, geographical information systems, modeling, Italy.

\section{Introduction}

Dirofilariosis are important parasitic diseases of dogs and other carnivores and, in Italy, they are due to Dirofilaria immitis and D. repens, both zoonotic infections. D. immitis is the causative agent of heartworm (HW) disease, and D. repens is the causative agent of canine subcutaneous dirofilariosis. The life

Corresponding author:

Laura Rinaldi

Dipartimento di Patologia e Sanità Animale

Facoltà di Medicina Veterinaria

Università degli Studi di Napoli "Federico II"

Via della Veterinaria, 1- 80137 Napoli, Italy

Tel. +39081 2536281; Fax +390812536282

E-mail: lrinaldi@unina.it cycle of both parasites consists of five larval stages developing both in a definitive vertebrate host and in an intermediate host, a mosquito that also acts as vector. Adult female worms in the vertebrate host produce blood embryos (first-stage larvae, microfilariae), and the typical diagnostic approach to differentiate $D$. immitis from $D$. repens infection is the morphological identification of microfilariae from peripheral blood, complemented by clinical, biochemical and molecular approaches (Casiraghi et al., 2005; Nelson et al., 2005). Microfilariae are taken up by a female mosquito when feeding on the infected animal. Microfilariae complete their development into infective third-stage larvae in the mosquito, depending on vector efficiency of the inverte- 
brate host and a number of external factors. Larval development in the mosquito is temperaturedependent with the time required decreasing gradually from a maximum at $14^{\circ} \mathrm{C}$ which is the threshold temperature for any development to proceed. The total environmental heat required for larval development may be expressed in terms of degreedays in excess of the $14^{\circ} \mathrm{C}$ threshold (HW development units - HDUs) (Fortin and Slocombe, 1981). The seasonal HW transmission model formulated by Slocombe et al. (1989) and re-evaluated by Lok and Knight (1998) in Canada and the US, respectively, assumes a requirement of $130 \mathrm{HDU}$ for $D$. immitis larvae to reach infectivity and a maximum life expectancy of 30 days for a mosquito vector.

Many European countries are endemic for Dirofilaria infections. In recent years, both infections appear to be spreading into areas previously considered to be free of the diseases (Genchi et al., 2005). In particular, autochthonous HW transmission in Europe has been reported as far north as Cherbourg $\left(50^{\circ} \mathrm{N}\right)$ in northern France (Doby et al., 1986).

HW infection is also spreading in Italy outside the classical hyperendemic areas along the Po River valley towards the central regions of the country, where the infection is now endemic (Genchi et al., 2005). In particular, in central Italy, the Umbria region was considered an uninfected area until 1999, with the exception of rare imported cases mainly from hunting dogs that had acquired the infection outside the region. Starting in 2000, the first observations of canine HW autochthonous foci were made and a survey, focused on prevalence and some putative risk factors (e.g. age, sex, outdoor night status, position, living together with other dogs), was performed in seven municipalities of the northern part of the Umbria region (Piergili Fioretti et al., 2003). The results suggested the existence of an autochthonous cycle of canine dirofilariosis in the northern part of the Umbria region, and an association between infection and age and outside nocturnal habitat was found. Since dog populations living in previously uninfected areas may not have developed sufficient natural protective immune responses to the disease, the further epidemiological monitoring of the infection has been recommended in order to better understand how wide the vector colonization of the territory could be, and how quickly the infection could spread among dogs. In this regard, it is recognized that global warming and the current climatic trend lead to extended transmission season and an increased incidence level of vector-transmitted diseases. In particular, it is reported that global warming can have an effect on the seasonal occurrence, distribution and spreading of HW infection (Genchi et al., 2005). Consequently, any attempt to identify the potential transmission period and infection risk in a defined geographical area should include an analysis of ecological variables. Among these, particular attention should be focused on meteorological factors like temperature, rainfall and humidity, and also on environmental factors like elevation of the areas were potentially exposed dogs are living (Attenborough et al., 1997; Brooker and Michael, 2000). Geographical information system (GIS) is a useful tool for the prediction of disease seasonality based on the climatic and/or environmental characteristics of a certain area and the information about the climatic and/or environmental requirements of a certain parasite species and its vector(s) (Cringoli et al., 2005; Rinaldi et al., 2006). Regarding HW infection, climate-based forecast models, combined with GIS, have been used in order to predict the occurrence and seasonality of D. immitis in the whole of Europe (Genchi et al., 2005), in the UK (Medlock et al., 2007) and in Argentina (Vezzani and Carbajo, 2006).

In the present study, a Dirofilaria prevalence survey targetted dogs in an area of central Italy, including some municipalities of the provinces of Perugia (Umbria region) and Arezzo (Tuscany region). The objectives of the study were:

(i) detection of new authochtonous cases;

(ii) confirmation of the increasing prevalence of Dirofilaria infections in the selected area;

(iii) evaluation of behavioural and attitudinal risk factors; 
(iv) environmental characterization (altitude, temperature, humidity and rainfall) of the study area; and

(v) estimation of the yearly number of $D$. immitis generations in the mosquito vectors in the study area for the identification of "hot spots" of HW transmission (Genchi et al., 2005).

The above inferences were established through statistical analysis of parasitological and serological findings in relationship with anamnestic records and environmental data, and through a GIS-based interpolation of climatic data collected from meteorological stations covering the study area.

\section{Materials and methods}

Study area, study cohort and questionnaire survey

The survey was carried out between March and July 2003 targetting dogs resident in the contiguous provinces of Perugia (Umbria region) and Arezzo (Tuscany region), covering an area of $11,671 \mathrm{~km}^{2}$
(Fig. 1). The survey was conducted by contacting nine veterinary practitioners working in the study area. Privately-owned dogs were enrolled in the study by random selection from those brought in for routine clinical examination. A questionnaire form was prepared to record the following data for each subject: breed, sex, age, attitude and/or utilization class (hunting/truffle dog, guard/pet dog), municipality of residence, outdoor/indoor night habitat, travels, and any symptomatology that could be related to dirofilariosis.

A total of 283 dogs from 20 different municipalities were enrolled in the study.

\section{Cross-sectional parasitological data}

Uncoagulated blood samples were taken from the enrolled dogs. Whole blood samples were analysed for the detection and species identification of circulating microfilariae by the modified Knott's test (Lindsey, 1965; Rawlings et al., 1993). In order to detect D. immitis occult infection (dogs infected

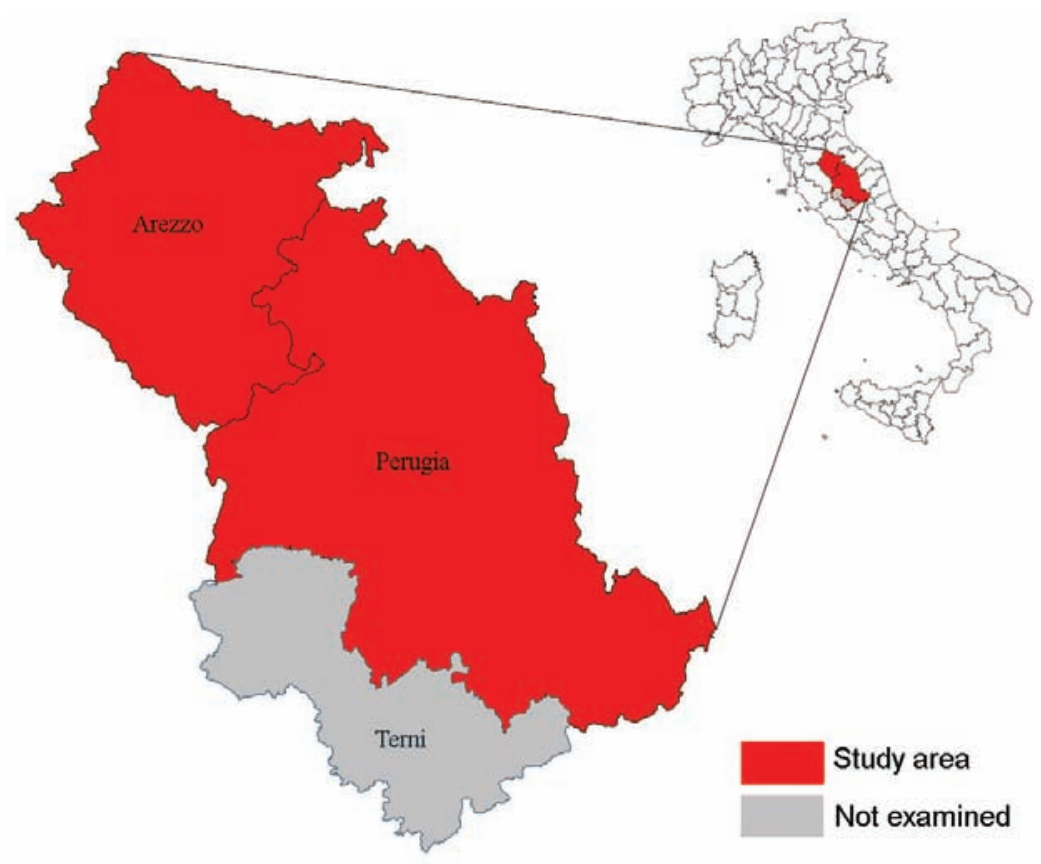

Fig. 1. Study area: the two contiguous provinces of Arezzo (Tuscany region) and Perugia (Umbria region). 
only by unisexual adult worms and negative to Knott's test), serum samples were analysed for D. immitis antigen using a commercial kit with no cross-reactivity to $D$. repens antigens (IDEXX PetCheck® HTWM PF, Maine, USA).

\section{Statistical analysis}

Sampled dogs were divided into different categories depending on the putative risk factors considered: breed, sex, age class $(0-2,2-5,>5$ years), attitude and/or utilization class (hunting/truffle dogs versus guard/pet dogs), and outdoor/indoor night habitat. The prevalence of Dirofilaria spp. infection and of the single parasitic species was calculated for each dog category. Data were analysed by the chisquared test to compare infection rates in different categories and values of $\mathrm{P}<0.05$ were considered significant. The statistical analysis was performed using Excel software for Windows.

\section{Development of GIS platform}

A GIS (software Arc-GIS 9.1, ESRI, Redlands, CA, USA) for the study area was constructed, utilizing the following data layers: administrative boundaries (at regional, provincial and municipal level), elevation, temperature, rainfall and humidity.

Elevation data for the study area were obtained from a digital elevation model (DEM) (with a spatial resolution of $100 \mathrm{~m}$ ).

Temperature, rainfall and humidity records related to the year of the study (2003) were collected from the following five geo-referenced meteorological stations located in the study area or near it in surrounding areas: Arezzo (latitude $=43^{\circ} 28^{\prime} \mathrm{N}$, longitude $=11^{\circ} 51^{\prime} \mathrm{E}$, Tuscany), Radicofani $\left(42^{\circ} 54^{\prime} \mathrm{N}\right.$, $11^{\circ} 46^{\prime} \mathrm{E}$, province of Siena, Tuscany), Santa Fista

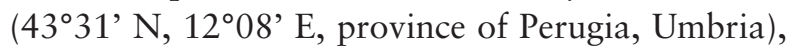
Marsciano $\left(43^{\circ} 00^{\prime} \mathrm{N}, 12^{\circ} 18^{\prime} \mathrm{E}\right.$, province of Perugia, Umbria), and Frontone (43 $31^{\circ}$ N, $12^{\circ} 44^{\prime}$ E, province of Pesaro, Marche). All these data were obtained from the Central Office of Agriculture Ecology (UCEA, Rome, Italy).

\section{Data-mapping}

In order to display the spatial distribution of D. immitis and D. repens in the study area, choroplethic maps (Cringoli et al., 2005; Rinaldi et al., 2006) were drawn using the municipality as geographical unit of reference and displaying the following information:

(i) Dirofilaria species studied (D. immitis, D. repens);

(ii) total study area, divided into municipalities;

(iii) municipalities with positive dogs;

(iv) municipalities without positive dogs; and

(v) municipal prevalence ( $\%$ ) determined as follows: (number of positive dogs in the municipality)/(number of dogs examined in the total study area) x 100 .

\section{Climate-based modeling}

Temperature records, spanning a 1-year period (2003), from the five meterological stations described above, were analyzed using the model described in Genchi et al. (2005).

For each station, the average monthly temperature was calculated from average maximum and average minimum temperatures from daily recordings. Temperature records were used for depicting the distribution maps of monthly average temperature and for the calculation of the cumulative HDUs for each meteorological station. The yearly average of the predicted number of HW generations in the study area was obtained through linear kriging interpolation (Genchi et al., 2005) within the GIS.

\section{Results}

\section{Study cohort and parasitological findings}

Among the 283 dogs enrolled, 272 were from municipalities located in the Perugia province and the remaining 11 from municipalities located in the Arezzo province. The altitude of the involved 
municipalities ranged from $191 \mathrm{~m}$ (Cannara municipality) to $500 \mathrm{~m}$ (Todi municipality) above sea level.

In total, 32 dogs out of the 283 studied $(11.3 \%$; $95 \%$ confidence interval $(\mathrm{CI})=8.0-15.7 \%)$ tested positive for either D. immitis or D. repens microfilariae: 29 out of $272(10.7 \%$; $95 \% \mathrm{CI}=7.4-15.1 \%)$ in Perugia province, and 3 out of $11(27.3 \%$; $95 \% \mathrm{CI}=$ 7.3-60.7\%) in Arezzo province.

Twenty dogs out of $283(7.1 \% ; 95 \%$ CI $=4.5$ $10.9 \%$ ) were positive for circulating D. immitis microfilariae: 17 out of $272(6.2 \%$; $95 \% \mathrm{CI}=3.8$ $10.0 \%$ ) in Perugia province, and 3 out of 11 $(27.3 \%$; $95 \% \mathrm{CI}=7.3-60.7 \%)$ in Arezzo province. Twelve dogs out of $283(4.2 \%$; $95 \%$ CI $=2.3-7.5 \%)$ were positive for circulating $D$. repens microfilariae: 12 out of $272(4.4 \%$; $95 \%$ CI $=2.4-7.8 \%)$ in Perugia province, and 0 out of $11(0 \%)$ in Arezzo province. Choroplethic maps showing the municipal prevalence of $D$. immitis and D. repens in the study area are depicted in Fig. 2. The highest positivity was found in Cannara municipality (Perugia province). Analysis of anamnestic data confirmed that only 3 dogs found positive to D. immitis and 1 dog found positive to $D$. repens showed clinical signs of the disease at the time of the examination.

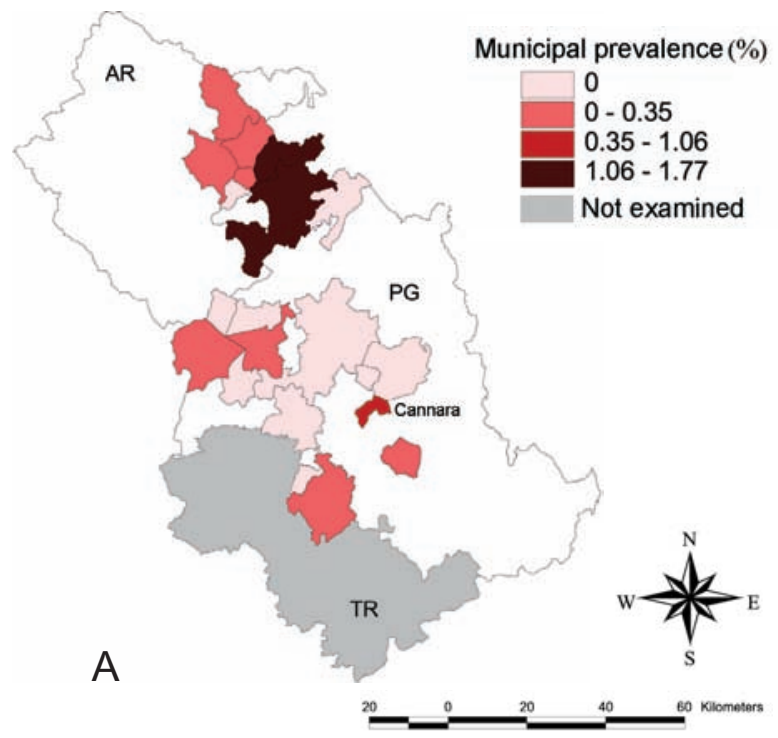

Two-hundred and three serum samples were subjected to detection of HW antigens and one case of D. immitis occult infection was also detected.

\section{Risk factors analysis}

The statistical analysis showed a significant $(\mathrm{P}<0.05)$ association between Dirofilaria infection and animal attitude (hunting/truffle dogs showed higher prevalence compared to guard/pet dogs), and age class (the higher prevalence were recorded in dogs aged 2-5 years, the intermediate prevalence in dogs $>5$ years, and the lower prevalence for dogs $<2$ years). No significant association was found between positivity and breed, sex and outdoor/ indoor night habitat. Among infected dogs, 20 out of $32(62.5 \% ; 95 \% \mathrm{CI}=43.7-78.3 \%)$ had never been outside the region of residence.

\section{Environmental data collection and analysis}

The climatological data regarding the year 2003 were expressed as average monthly values for each month respectively for temperature, humidity and rainfalls (Fig. 3). The distribution maps of monthly average temperature in the study area in the year

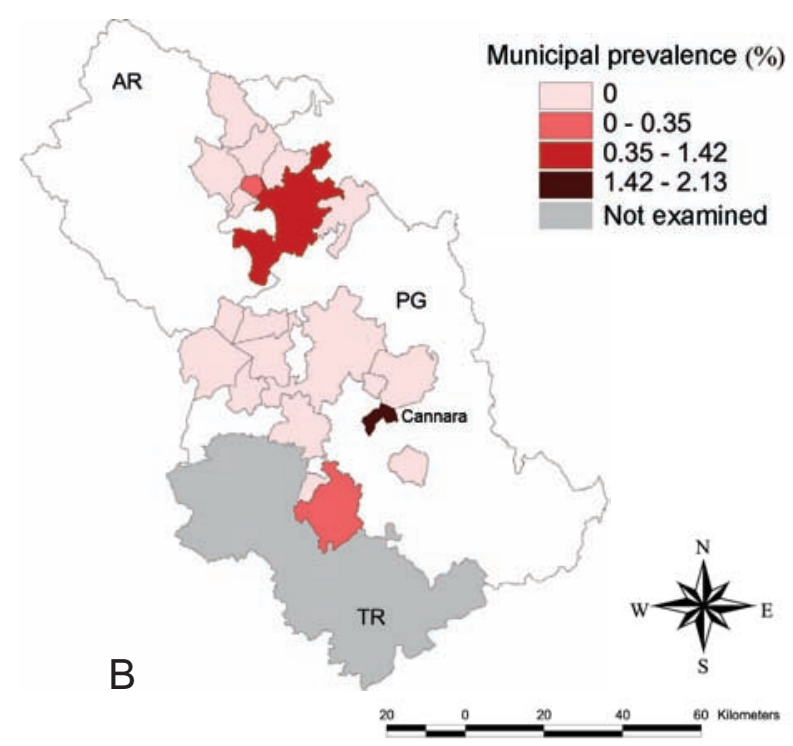

Fig. 2. Municipal prevalence of D. immitis (A) and D. repens $(\mathrm{B})$ in the study area (AR = Arezzo; PG = Perugia; TR = Terni). 
2003 are shown in Fig. 4. The number of generations in the study area was estimated for the identification of the "hot spots" of HW transmission (Fig. 5 ). The results showed that the local climate generally ensures the conditions for the establishment and maintenance of the parasite cycle in the area. The temperature patterns more favourable to parasite development in the mosquito, as depicted in the study area maps for months May-July 2003, strongly overlap the focal points of territorial distribution of positive dogs. In these foci, the suitable period for the maturation of infective third stage larvae starts at the beginning of June and encompasses July and August. From September onwards, the cumulative HDUs are insufficient to sustain the development of the parasite in the mosquito.

\section{Discussion}

Epidemiological studies conducted in recent years showed that canine dirofilariosis is spreading throughout previously uninfected European areas with an increasing force (Trotz Williams and Trees, 2003; Genchi et al., 2005; Medlock et al., 2007). In the present study, initiated by early observations at the beginning of the new millennium, the presence of both $D$. immitis and D. repens species, even with different prevalence values, in the Perugia province was confirmed. The prevalence of D. immitis infection was higher than that reported in previous studies recently performed in the same area, and was focused on a limited number of municipalities with the higher positivity found at the municipality of Cannara (Perugia province). As expected from past experiences in canine dirofilariosis, risk factor analysis conducted in the present study underlined the importance of life habits of the dogs rather than of the breed itself. The high percentage of infected dogs with no travelling anamnesis could be an indication of the existence of a large number of new microfoci of autochthonous infection. Only four dogs out of 32 found positive, showed clinical signs of the disease, confirming that even in new endemic foci the infection is generally asymptomatic even when microfilariaemia is fairly developed. These facts enforce the need for rigorous monitoring strategies for early detection of autochthonous cases in order to start prophylactic measures to control new infection foci before they are definitely established.

The climatic variables analysis based on the data collected from the geo-referenced meteorological stations confirmed the environmental conditions favourable to the Dirofilaria life cycle in the study area, leading to increased infection risk when other hazardous individual conditions (attitude, night habit, ect.) are present. In particular, a relatively high humidity level is provided during most of, if
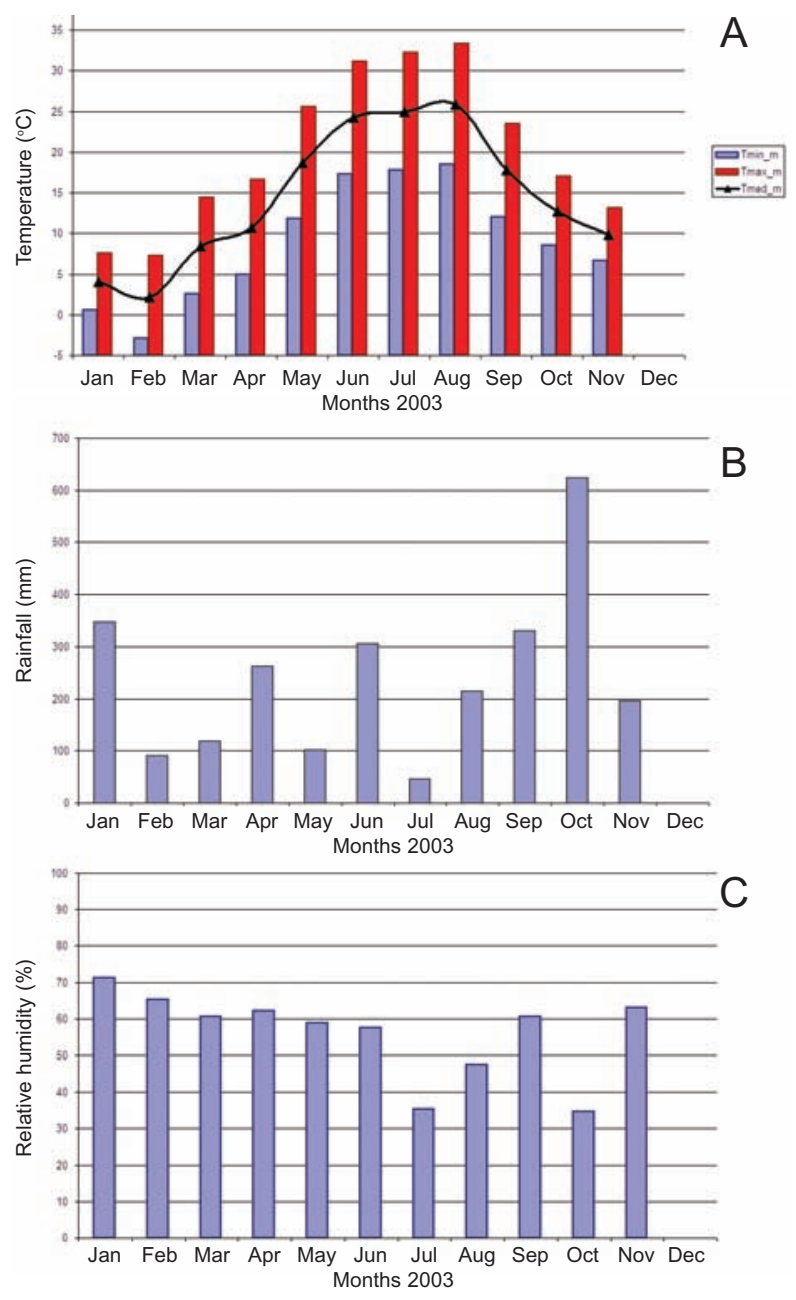

Fig. 3. Average monthly temperature (A), rainfall (B) and humidity (C) in the study area in the year 2003. 
not all, the year as a combined result of abundant rainfalls and the presence of numerous rivers and Trasimeno lake in central Italy. The HDUs distribution and vector generation numbers in the northern part of Umbria, as depicted by GIS analysis, is highly concordant with the territorial distribution of positive dogs and show that filarial spread is markedly influenced by season. The potential transmission period is confined to the summer months with a peak in July and August, as expected for a temperate region where the summer season is the
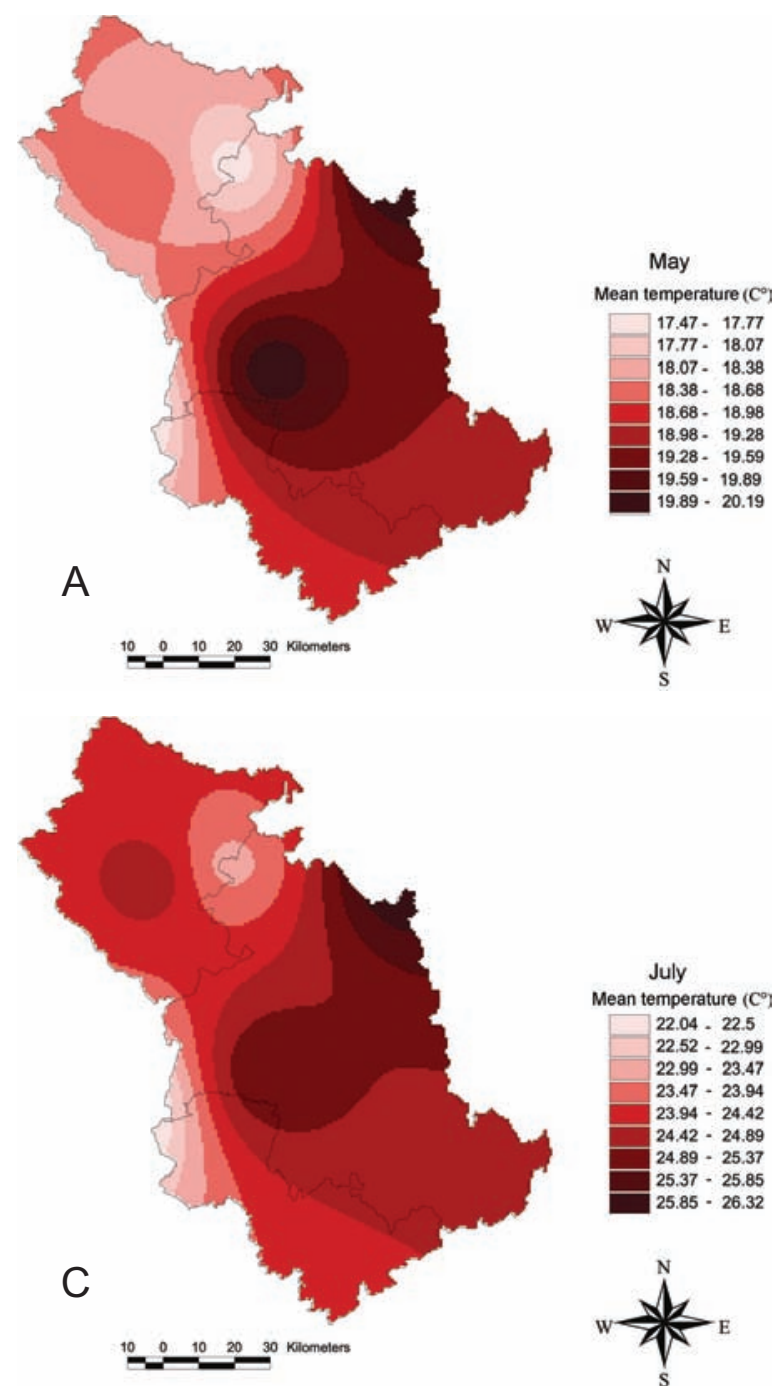

most favourable to mosquito activity. Micro-environmental variations could explain the differences observed in prevalence rates even among close municipalities; it should be noted that the highest positivity was found in the Cannara municipality, located at the lower altitude. With the availability of more detailed microclimatic and microecological data, further GIS-based analysis could help to better delineate areas at risk. It is clear that if the actual trend of temperature increase continues, the infection could, in the near future, spread into currently
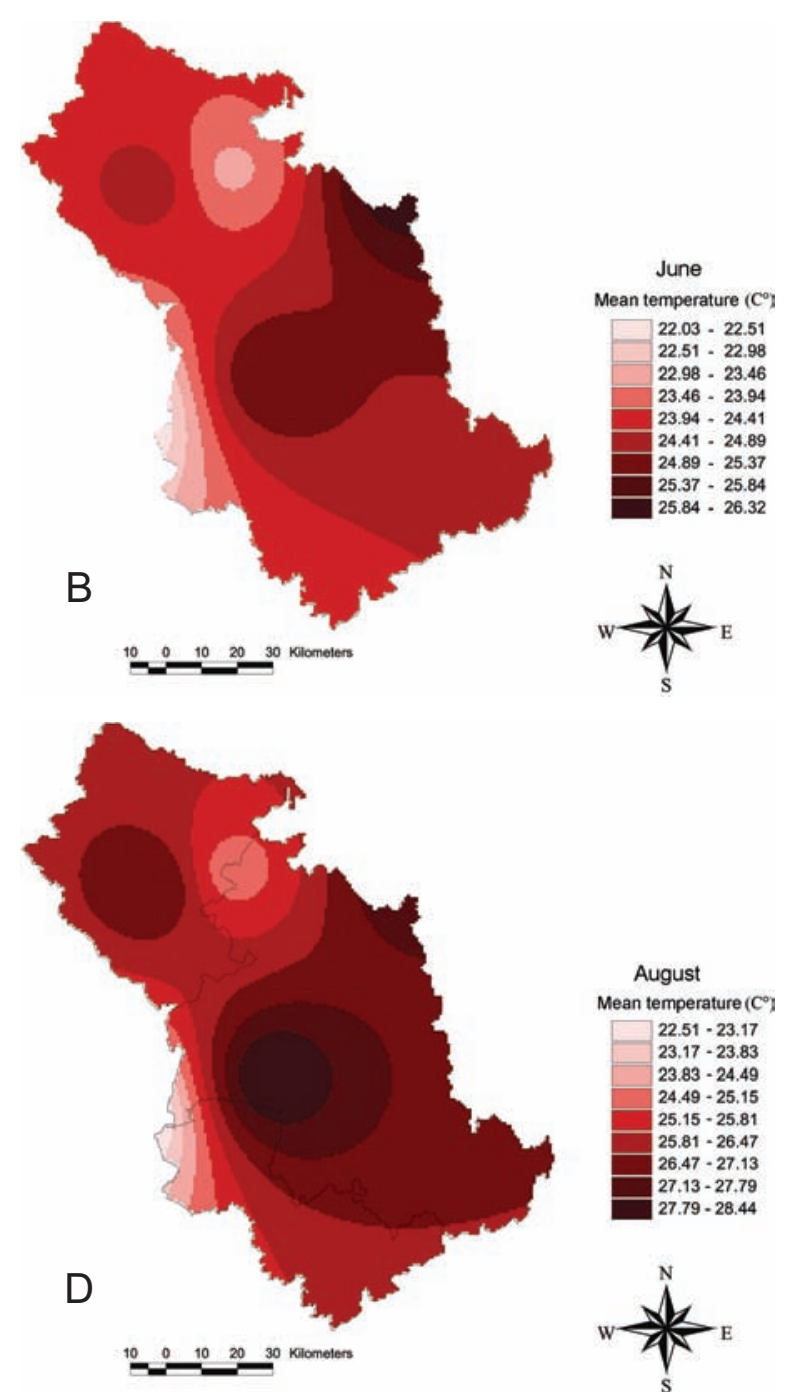

August Mean temperature $\left(\mathrm{C}^{\circ}\right)$ $22.51-23.17$ $22.51-23.17$
$23.17-23.83$ $23.17-23.83$
$23.83-24.49$ $24.49-25.15$ $25.15-25.81$ $25.81-26.47$ $26.47-27.13$ $27.13-27.79$ $27.79 \cdot 28.44$

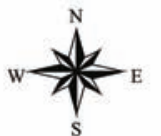

Fig. 4. Mean temperature maps of the study area obtained from the GIS linear kriging interpolation for the months of May (A), June (B), July (C), and August (D) in the year 2003. 
non-infected areas. In the southern part of Umbria (Terni province), in spite of climatic and environmental conditions already favourable to the spread of the infection, so far no autochthonous cases have been reported in the literature. This negative finding could, at least in part, be determined by the prompt and massive prophylactic campaign against HW infection taken up by veterinary practitioners in the area (Piergili Fioretti et al., 2003).

The results of the present study confirm that GIS is a useful tool for making inferences about the relationship between the environment and the disease. In addition to dirofilariosis studies (Genchi et al., 2005; Vezzani and Carbajo, 2006; Medlock et al., 2007), climate-based forecast systems employing the concept of growing degree days (GDD) and the use of GIS, have also been developed for different vector-borne and water-associated diseases of parasitological importance, such as fascioliasis, schistosomiasis, onchocerciasis, leishmaniasis, and malaria (e.g. Malone, 2005; Yang et al., 2006).

The Dirofilaria risk maps, discussed in the present study and in others, could be used by practitioners and health authorities to efficiently direct surveillance and control efforts. From a general point of view, epidemiological surveillance employing the use of GIS is characterized by an integrated set of planned epidemiological activities with the aim to identify and prevent new cases of disease. Such a system is justified provided the natural history of the disease and its determinants are known and effective preventive strategies are available.
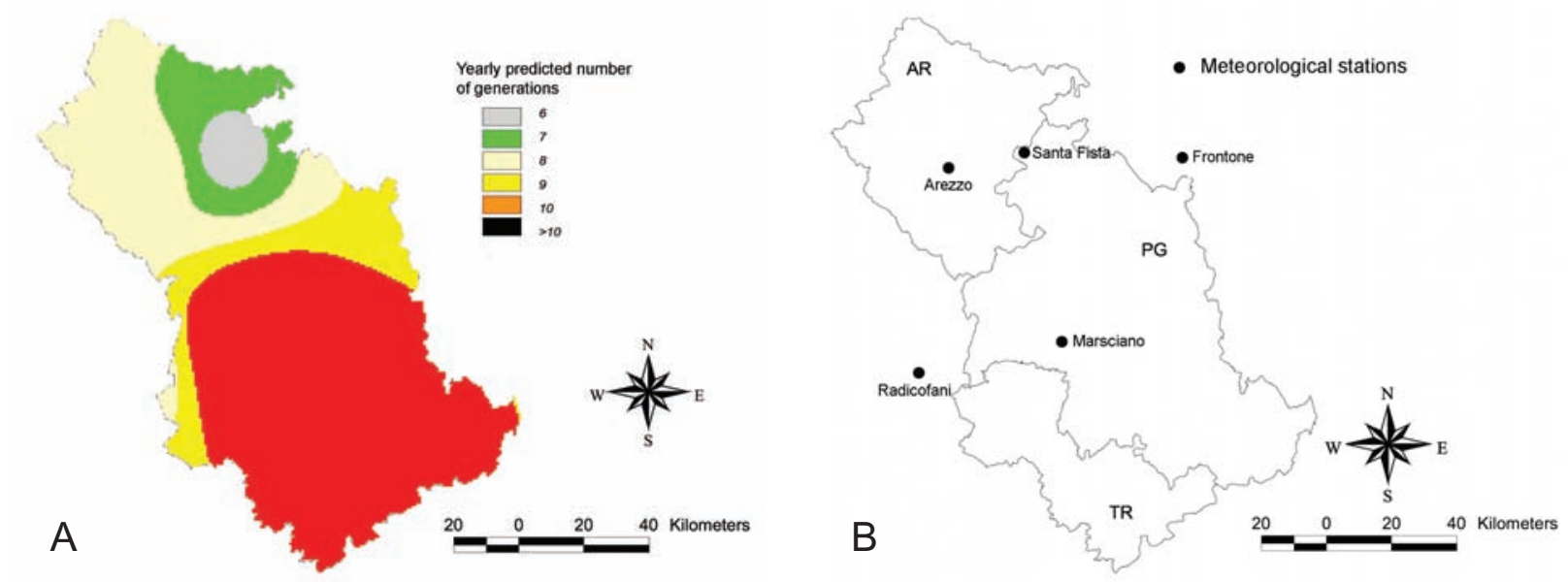

\begin{tabular}{|c|c|c|c|c|}
\hline Station & April & May & June & July \\
\hline Santa Fista (Perugia) & $<130$ HDUs & $<130$ HDUs & $>130$ HDUs & $>130$ HDUs \\
\hline Marsciano (Perugia) & $<130$ HDUs & $>130$ HDUs & $>130$ HDUs & $>130$ HDUs \\
\hline Frontone (Pesaro) & $<130$ HDUs & $>130$ HDUs & $>130$ HDUs & $>130$ HDUs \\
\hline Arezzo & $<130$ HDUs & $>130$ HDUs & $>130$ HDUs & $>130$ HDUs \\
\hline Radicofani (Siena) & $<130$ HDUs & $<130$ HDUs & $>130$ HDUs & $>130$ HDUs \\
\hline Station & August & September & October & November \\
\hline Santa Fista (Perugia) & $>130$ HDUs & $<130$ HDUs & $<130$ HDUs & $<130$ HDUs \\
\hline Marsciano (Perugia) & $>130$ HDUs & $>130$ HDUs & $>130$ HDUs & $<130$ HDUs \\
\hline Frontone (Pesaro) & >130 HDUs & $<130$ HDUs & $<130$ HDUs & $<130$ HDUs \\
\hline Arezzo & $>130$ HDUs & $>130$ HDUs & $<130$ HDUs & $<130$ HDUs \\
\hline Radicofani (Siena) & $>130$ HDUs & $>130$ HDUs & $>130$ HDUs & $<130$ HDUs \\
\hline
\end{tabular}

Fig. 5. HDUs calculation through GIS linear kiriging. A: total number of predicted yearly generation. B: georeferenced meteorological stations that reached (grey background) or did not reach (blank background) the minimum cumulative 130 HDUs between April and November in the year 2003. 


\section{References}

Attenborough RD, Burkot TR, Gardner DS, 1997. Altitude and risk of bites from mosquitoes infected with malaria and filariasis among the Mianmin people of Papua New Guinea. Trans R Soc Trop Med Hyg 91, 8-10.

Brooker S, Michael E, 2000. The potential of geographical information systems and remote sensing in the epidemiology and control of human helminth infctions. Adv Parasitol 47, 246-279.

Casiraghi M, Bazzocchi C, Mortarino M, Ottina E, Genchi C, 2005. A simple molecular method to discriminate common filarial nematodes of dogs (Canis familiaris). Vet Parasitol 141, 368-372.

Cringoli G, Rinaldi L, Veneziano V, Musella V, 2005. Disease mapping and risk assessment in veterinary parasitology: some case studies. Parassitologia 47, 9-25.

Doby JM, Guiguen C, Lefevre R., 1986. Présence de Dirofilaria immitis (Leidy, 1856) chez le chien en Bretagne.

Bull Soc Franc Parasitol 4, 51-54.

Fortin JF, Slocombe JOD, 1981. Temperature requirements for the development of Dirofilaria immitis in Aedes triseriatus and Ae. vexans. Mosq News 41, 625-633.

Genchi C, Rinaldi L, Cascone C, Mortarino M, Cringoli G, 2005. Is heartworm disease really spreading in Europe? Vet Parasitol 133, 137-148.

Lindsey LR, 1965. The identification of canine microfilariae. J Am Vet Med Assoc 146, 1106-1114.

Lok JB, Knight DH, 1998. Laboratory verification of a seasonal heartworm transmission model. In: Proceedings of the Advances in Heartworm Disease, Symposium 1998, RL Seward (ed), pp. 15-20.

Malone JB, 2005. Biology-based mapping of vector-borne parasites by geographic information systems and remote sensing. Parassitologia 47, 27-50.
Medlock JM, Barrass I, Kerrod E, Taylor MA, Leach S, 2007. Analysis of climatic predictions for extrinsic incubation of Dirofilaria in the United Kingdom. Vector Borne Zoonotic Dis 7, 4-14.

Nelson CT, McCall JW, Rubin SB, Buzhart LF, Doiron DW, Graham W, Longhofer SL, Guerrero J, Robertson-Plouch C, Paul A, 2005. Guidelines for the diagnosis, prevention and management of heartworm (Dirofilaria immitis) infection in dogs. Vet Parasitol 133, 267-275.

Piergili Fioretti D, Diaferia M, Grelloni V, Maresca C, 2003. Canine filariosis in Umbria: an update of the occurrence one year after the first observation of autochthonous foci. Parassitologia 45, 79-83.

Rawlings CA, Tonelli Q, Lewis RE, Duncan JR, 1993. Semiquantitative test for Dirofilaria immitis as a predictor of thromboembolic complications associated with heartworm treatment in dogs. Am J Vet Res 54, 914-919.

Rinaldi L, Musella V, Biggeri A, Cringoli G, 2006. New insights into the application of geographical information systems and remote sensing in veterinary parasitology. Geospatial Health 1, 33-47.

Slocombe JOD, Surgeoner GA, Srivastava B, 1989. Determination of the hearthworm transmission period and its use in diagnosis and control. In: Proceedings of the Heartworm Symposium 1989, GF Otto (ed), pp. 19-26.

Trotz Williams LA, Trees AJ, 2003. Systematic review of the distribution of the major vector-borne parasitic infections in dogs and cats in Europe. Vet Rec 152, 97-105.

Vezzani D, Carbajo AE, 2006. Spatial and temporal transmission risk of Dirofilaria immitis in Argentina. Int J Parasitol 36, 1463-1472.

Yang GJ, Gemperli A, Vounatsou P, Tanner M, Zhou XN, Utzinger J, 2006. A growing degree-days based time-series analysis for prediction of Schistosoma japonicum transmission in Jiangsu province, China. Am J Trop Med Hyg 75, 549-555. 